\title{
A hierarquização simbólica do Brasil na Copa do Mundo*
}

Michel Nicolau Netto**

Resumo: A pertinência de se sediar a Copa do Mundo, tornou-se, para o Brasil, um tema controverso entre 2013 e 2014, focando-se os debates em dois elementos de disputa: os impactos econômicos e sociais do evento. Um terceiro elemento, contudo, também fora mobilizado, mas pareceu bem menos contestado. Argumentava-se que sediar a Copa do Mundo se justificaria pela promoção da imagem do Brasil no exterior. Esta proposta surge justamente em uma situação de economia globalizada, na qual países em todo o mundo disputam a atração de um capital flexível e desnacionalizado. Nesse sentido, as identidades são articuladas como marca no intuito de se produzir o espaço simbolicamente como mais atraente a esse capital, o que se nota, em especial, na promoção turística. Este artigo busca compreender a relação entre a formação das marcas-lugar empreendida pelos órgãos de turismo nacionais, e a promoção da imagem do país no contexto da Copa do Mundo. Será demonstrado, no caso brasileiro, que a pluralidade de agentes interessados na representação do Brasil leva à hierarquização dessas representações, hierarquização que se dá, contudo, não a partir do Estado-nação, mas de empresas globais envolvidas com o megaevento.

Palavras-chave: Copa do Mundo, nacionalismo corporativo, identidade nacional, Embratur, Brasil.

N os meses que antecederam à Copa do Mundo de futebol de 2014, defensores e descontentes se engajaram em intensa disputa relativa à pertinência do evento. Dois temas galvanizaram os embates: direitos humanos e custos. Um terceiro tema também esteve presente, servindo de fundamento central para os defensores do megaevento: a melhoria da imagem do país no exterior. Contudo, esse último não entrou em debate do mesmo modo que os outros dois, sendo justamente o tema deste artigo. Antes de apresentá-lo, lembremo-nos rapidamente como os outros temas foram tratados.

O debate sobre os custos da Copa do Mundo se centrou nos sentidos do valor anunciado, em torno de R\$ 26 bilhões ${ }^{1}$. Não se disputava a correção do número, mas sua interpretação. Dentro de uma retórica desenvolvimentista adotada pelo governo federal, em especial a partir de 2007 (Sampaio Júnior, 2012), este buscou, inicialmente, compreender aquele valor como investimento, a força motriz de uma nova fase de modernização do país. Dessa forma, a matriz de responsabilidades da Copa (primeira versão de 2010 e última de 2013)² não se restringiu apenas aos custos estritamente necessários para os jogos, aqueles relativos a estádios, entorno e apareIhagem tecnológica de transmissão. Em uma clara intenção de relacionar o custo da Copa a investimentos em um "Brasil maior"

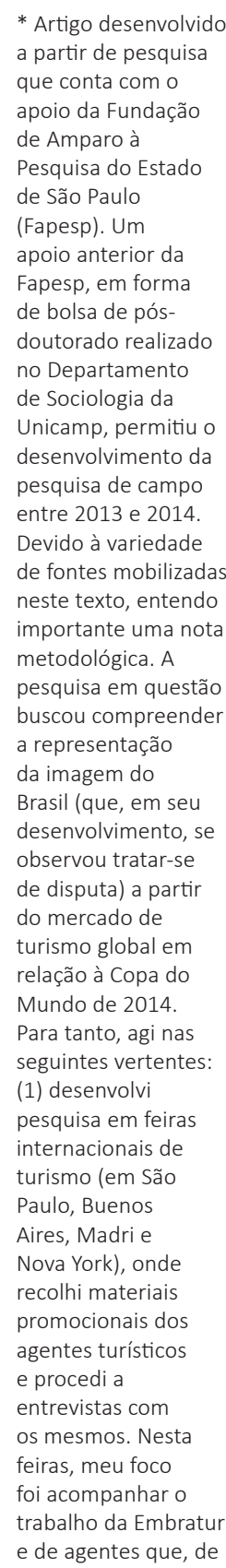

* Artigo desenvolvido que conta com apoio da Fundação de Amparo à de São Paulo (Fapesp). Um apoio anterior da Fapesp, em form doutorado realizado no Departament de Sociologia da amp, permitiu o pesquisa de campo de fontes mobilizadas neste texto, entendo importante uma nota pesquisa em questão buscou compreender a representação magem do desenvolviment observou tratar-se de disputa) a partir turismo global em relação à Copa do Mundo de 2014. tanto, agi nas (1) desenvolvi pesquisa em feira internacionais de rismo (em São Nova York), ond recolhi materiais e procedi a entrevistas com mesmos. Nesta foi acompanhar e de agentes que, de 
alguma forma, com ela se relacionam; (2) aprofundei-me na investigação sobre o setor turístico em três cidades-sede da Copa (São Paulo, Rio de Janeiro e Cuiabá), nas quais permaneci ao menos por 20 dias, e busquei compreender o processo de produção simbólica dessas cidades em relação ao evento esportivo, visitei os principais pontos turísticos, entrevistei diversos representantes de governo e agentes de turismo, recolhi materiais; (3) realizei análise de documentos, especialmente das cidades citadas e da Embratur, com foco naqueles que se relacionaram à Copa do Mundo; (4) procedi à análise dos agentes envolvidos com a Copa do Mundo, como Fédération Internationale de Football Association (Fifa) e movimentos contrários à Copa do Mundo. Neste caso, realizei entrevistas com alguns dos agentes, participei de eventos nos quais os mesmos estavam envolvidos e analisei documentos. Todas as assertivas deste texto são baseadas em reflexões realizadas a partir desses procedimentos de pesquisa. Às vezes, utilizei-me de exemplo como forma ilustrativa, tendo ciência de que o exemplo explica o todo da reflexão. flá-los e, desta forma, empenhou mais da metade do orçamento da Copa em custos não relacionados ao evento, que se referem a todas as ações que, embora relativas, não eram necessárias à realização dos jogos: estradas, sinalização turística, aeroportos, meios de transporte público etc. Essa diferenciação entre custos relacionados e não relacionados dos megaeventos, como propõe Holger Preuss (1998), é o que torna a comparação entre os custos totais de um evento com outro (por exemplo, da Copa no Brasil com a Copa na África do Sul) difícil, pois em geral baseia-se em dados diferentes. O que me interessa aqui notar, de qualquer modo, é que no caso brasileiro o alto valor de custos não relacionados se deveu, centralmente, à política e à retórica desenvolvimentista do governo federal.

No momento de conflito em relação à Copa do Mundo, os números ganharam novo significado: para os descontentes com os jogos, os investimentos se tornaram desperdício e propôs-se que os valores fossem aplicados em outras áreas. Assim, no Dossiê da Associação Nacional dos Comitês Populares da Copa, que reuniu movimentos sociais críticos ao evento no Brasil, lê-se:

\begin{abstract}
O investimento necessário para colocar 3,7 milhões de crianças e adolescentes brasileiras, de 4 a 17 anos, nas escolas é de aproximadamente $\mathrm{R} \$ 25,3$ bilhões, um pouco menos do que os gastos totais da Copa. [...] Outro destino possível para o dinheiro da Copa seria a saúde. [...] A verba destinada para a Copa poderia ser revertida em transporte público e ainda ia sobrar. Um estudo do Ipea de 2013 mostrou que a adoção do passe livre para estudantes e do vale transporte social custaria $\mathrm{R} \$ 15,3$ bilhões, pouco menos da metade do que custou a Copa (Ancop, 2014: 101).
\end{abstract}

Interessante observar que essa retórica foi eficaz e levou o governo a dar outro sentido aos custos. Próximo ao evento e às eleições, após os conflitos de 2013, o governo lançou uma série de ações na mídia pelas quais buscou, então, minimizar os números, comparando-os com orçamentos inteiros destinados à saúde ou à educação. Dessa forma, aquilo que era percebido como algo maior, agora devia ser visto como algo diminuto: a Copa não custa tanto assim, quis propor o governo. Como em uma brincadeira de perspectiva, os críticos dos custos do evento colocavam o boneco ao lado do anão; os defensores, agora, ao lado do gigante.

Outro debate de ampla repercussão se deu em relação aos direitos humanos, que, por sua vez, se referiram em especial a questões relacionadas às desapropriações e aos deslocamentos (segundo a nomenclatura oficial do governo federal) ou às remoções (termo utilizado pelos movimentos sociais organizados em torno dos Comitês Populares da Copa). De acordo com estes, foram removidas 250 mil pessoas 
no Brasil (Ancop, 2014: 42) em prol da "elitização e a privatização da cidade" (Portal Popular da Copa e das Olimpíadas, 2014). Para o governo, contudo, foram desapropriadas ou deslocadas involuntariamente 35.653 pessoas (Secretaria Geral da Presidência da República, 2014), uma consequência considerada aparentemente necessária para a realização de um evento que, supunha-se, levaria a um crescimento do PIB (Ernst \& Young, s/d; Valente Júnior, s/d) e, dessa forma, a melhoria da vida da população de baixa renda, de acordo com a retórica governamental. Dessa forma, além da discordância dos números, houve um intenso debate ideológico que se referiu à própria nomenclatura de um processo real que impactou diretamente a vida das pessoas e a luta pela cidade, o que mobilizou diferentes visões e utopias sobre o papel do poder público e do capital ${ }^{4}$.

Os dois debates sumariamente narrados demonstram que os grupos representantes de diferentes interesses e visões souberam colocar-se claramente de acordo com essas posições através da mobilização de números e ideologias. Contudo, tal clareza não levava a nenhuma conciliação, pois, ao contrário, a aparente certeza que trazia permitia a cada grupo se fiar ainda mais em seus dados, não havendo a necessidade da concessão ao argumento do outro. Tudo se passava como se a correção de um dado ou de uma ideologia legitimasse uma verdade para cada grupo que não precisava ser negociada. Diferentemente se passava com o terceiro debate, que é o tema deste artigo. Por sua própria lógica discursiva, que coloca em um futuro incerto a possibilidade de avaliação, e que se baseia em visões subjetivas de difícil mensuração, o argumento sobre a melhoria da imagem do Brasil no exterior parece ter passado ileso às controvérsias.

Notemos que este argumento é central na justificativa de sediar os megaeventos. Lula afirmou em, 2007, na abertura da jornada para a Copa do Mundo, que "com o Mundial, teremos a oportunidade de apresentar ao mundo um novo momento do Brasil" (Ivo, 2011: 47). O ex-presidente da Embratur e da SPTuris ${ }^{5}$, Caio de Carvalho, em sua tese de doutorado, afirmou:

O retorno da imagem para o país, e para destinos turísticos como São Paulo que sediarão os jogos, é imensurável, dada as proporções que o evento assume no conhecido "país das chuteiras" (Carvalho, 2009: 199).

Do mesmo modo, no plano turístico do município de São Paulo, afirmava-se que a

Copa do Mundo Fifa 2014 permitirá reforçar a imagem de São Paulo como um destino turístico que oferece ao paulistano e a seu visitante as melhores opções de cultura, lazer e entretenimento (São Paulo Turismo, 2010: 92).
** Professor do Departamento de Sociologia do Instituto de Filosofia e Ciências Humanas da Unicamp. <mnicolau@ unicamp.br>.

1. Fonte: Portal da transparência. Disponível em: <http://www. portaltransparencia. gov.br/copa2014/ home.seam>. Acessado em: 11 Dez. 2014.

2. Disponível em: <http://www. copa2014.gov. br/sites/default/ files/131126 anexo2_resolucao gecopa.pdf>. Acessado em: 8 Out. 2014. Este é o documento que institui as responsabilidades e os gastos de cada ente envolvido na realização dos jogos.

3. Brasil maior é o nome do plano estratégico do Ministério do Desenvolvimento Indústria e Comércio Ver: <http://www. brasilmaior.mdic.gov. br>. Acessado em: 6 Nov. 2014. O plano foi lançado em 2011.

4. É importante destacar que nenhuma das questões discutidas aqui se refere exclusivamente ao Brasil. Por aqui, o ineditismo se deu em referência à dimensão dos debates, que tomaram uma parcela significativa da população, por razões que 
certamente vão mais longe do que o evento em si, abrangendo os processos de acirramento político, em torno de diversas formas de estratificação social, que encontraram seu ápice nas eleições de 2014. Mas de forma alguma o conteúdo é inédito. Na maior parte, senão em todos os megaeventos contemporâneos - Maurice Roche (2000) elenca, tipicamente, os Jogos Olímpicos, a Copa do Mundo de Futebol e as Exposições Universais -, essas questões surgiram. Em relação aos direitos humanos e às remoções, por exemplo, organizações de direitos humanos afirmam que as Olimpíadas de Pequim teriam sido responsáveis pela remoção de 1,5 milhão de pessoas (Institute for Human Rights and Business, 2013). Em relação aos impactos econômicos, na África do Sul, a expectativa do governo era que a Copa de 2010 elevasse entre 3 e $5 \%$ o crescimento do PIB, enquanto seus críticos garantiram que o objetivo não alcançou 0,5\% (de Paula \& Bartelt, 2014: 92). De fato, críticos em geral argumentam que "existem indicadores para pensarmos numa tendência de superestimação dos benefícios
Ademais, o projeto estratégico de turismo elaborado pela Fundação Getúlio Vargas (FGV) por demanda do Ministério do Turismo, tendo em vista os megaeventos, aconselhava:

\begin{abstract}
A promoção adequada de uma cidade-sede requer a elaboração de um planejamento de marketing capaz de identificar em que segmentos de mercado o destino quer se mostrar, ou se revelar, ao país e ao mundo (Mtur e FGV, s/d: 25).
\end{abstract}

A promoção internacional se torna, assim, um eixo central na justificativa de se sediar um megaevento, sendo assumida como importante legado (Tavares, 2011: 22):

De fato, alguns argumentariam que se a marca do evento não é o sucesso financeiro a curto prazo, a reforma da imagem da cidade, de seu lugar no mapa mental internacional, enquanto impossível de quantificar, pode no fim mais do que compensar (Holcomb, 1999: 60).

Como coloca um importante jornalista dedicado aos bastidores do poder esportivo,

para os países emergentes, a Copa, os Jogos Olímpicos e outros grandes eventos se transformaram em braços de uma estratégia de projeção internacional. São, na realidade, atalhos para saltar etapas no reconhecimento global (Chade, 2014).

Ao adiantar um termo que será explorado neste artigo - marca-lugar -, o primeiro ministro sul-coreano, Jin Nyum, justificou a Copa do Mundo de 2002 em seu país ao dizer que se tratava de "'construção de marca [brand-making] da Coreia, muito mais do que fazer dinheiro diretamente" (Horne \& Manzenreiter, 2004: 193).

Este artigo busca tratar deste tema, mas sob uma perspectiva diferente da lógica que embasou os debates descritos acima. Não importa aqui um saber normativo, como avaliar se o megaevento melhora ou não a imagem do país no exterior, mas atentar a três questões: em primeiro lugar, do que se trata falar de uma imagem do país. Este tema deve ser compreendido pela relação a uma reorganização produtiva global que torna a imagem do país um fator central de atração de um capital desnacionalizado e flexível. Em segundo lugar, é necessário que se compreenda quem são os agentes interessados na produção dessa imagem. Na globalização, o Estado-nação perde o monopólio de produção da imagem do país e diversos agentes se integram neste processo, disputando as condições dessa produção ${ }^{6}$. Ao se considerar, portanto, que a imagem do país é produzida por diversos agentes em conflito, deve-se perguntar, por fim, quais as condições que a Copa do Mundo apresenta para essa produção e como isso beneficia certos agentes, mas prejudica outros. 0 
artigo se organiza em torno desses temas. Dito isso, também alerto sobre algo não examinado pelo artigo: não apresentarei aqui qualquer discussão substantiva sobre qual imagem do Brasil se promove.

\section{A produção simbólica do espaço}

Mais impactante talvez, mas correlativo, do que os processos de desmontagem do aparelho público empreendido no mundo, muito especialmente a partir da década de 1990, é a adoção na esfera pública de uma racionalidade tipicamente empresarial em substituição à racionalidade burocrática. Se Weber, apesar das críticas, pensava a burocracia como elemento central do estado democrático (Weber, 1958), ela hoje é condenada e contraposta a um Estado ideal. Este Estado deve ser gerido pela lógica da eficiência e do empreendedorismo, adotando procedimentos, ainda que mantidos na esfera pública, típicos de lógica de empresa. Há nos serviços públicos uma "mudança para o empreendedorismo na governança urbana", como afirma David Harvey:

Em outras palavras, a abordagem "administrativa", tão característica na década de 1960, deu lugar a formas de ação iniciadoras e "empreendedoras" nas décadas de 1970 e 1980. Nos anos recentes, em particular, parece haver um consenso geral emergindo em todo o mundo capitalista avançado: os benefícios positivos são obtidos pelas cidades que adotam uma postura empreendedora em relação ao desenvolvimento econômico (Harvey, 2005: 165).

O sentido empreendedor do setor público se declina em uma competição cada vez mais globalizada entre países e cidades. O capital transnacional, flexível, que facilmente se movimenta de um lugar para outro, traz duas consequências, no âmbito da perspectiva que me interessa aqui. De um lado, passa a haver uma constante incerteza dos lugares quanto à permanência desse capital em seus espaços. Nem mesmo as bordas do Estado-nação representam hoje qualquer limite para a circulação do capital que pode em um dia produzir um espaço que no momento seguinte será devastado. De outro lado, essa mobilidade faz com que pareça possível a qualquer lugar disputar a aterrissagem, ainda que momentânea, desse capital. De uma forma e de outra - para buscar a permanência ou para atrair a aterrissagem - os lugares se veem incumbidos em adotar as estratégias que Harvey chamou de empreendedoras.

Os lugares, ao contrário do que se suponha, portanto, não desaparecem com o processo de globalização (Ortiz, 2003). A insistência de Saskia Sassen sobre a importância de se estudar a globalização não nos processos tipicamente globais (nos fluxos financeiros, por exemplo), mas nas cidades, se dá justamente porque econômicos e sociais, assim como das rendas geradas e a subestimação dos custos e dos impactos (Gratton et alii, apud Tavares, 2011)", enquanto alguns autores propõem métodos que buscam "calcular" os impactos econômicos dos eventos. Em relação à promoção da imagem do país como este artigo debaterá, a questão também é global.

5. São Paulo Turismo empresa de capital aberto, que tem a prefeitura de São Paulo como sócia majoritária.

6. Minha apreciação sobre o tema é amplamente influenciada pela noção de poder simbólico de Pierre Bourdieu (2004). O que busco fazer é compreender os elementos $\mathrm{e}$ as condições de disputa de agentes que buscam afirmar imagens que vinculam a própria produção simbólica dos outros. 
os mercados nacionais e globais, assim como organizações globalmente integradas, requerem lugares centrais onde o trabalho da globalização é feito (Sassen, 2007: 108).

O fluxo global de capital precisa, portanto, do lugar para se valorizar, o que torna nações e cidades instâncias de ordenação de formas para atração desse capital. Neste sentido, elas concorrem umas com as outras seja para atração do capital em forma de investimentos em produção - empresas transnacionais que se estabelecem em certos lugares em detrimento de outros em razão da oferta de benefícios e serviços -, em consumo (Harvey, 2005: 172) ou ainda em especulação financeira.

O turismo torna-se na contemporaneidade uma forma privilegiada de valorização deste capital no lugar. O turismo tem sua história, que aqui não me interessa retomar (Fainstein \& Judd, 1999; Rejowski, 2002). O que me importa é que desde a década de 1970, ele se tornou parte de uma estratégia de recomposição econômica de grandes centros urbanos que passaram por intensivos processos de desindustrialização (Roche, 1992: 564). Dessa forma, a partir desse momento, não apenas os espaços construídos exclusivamente para o turismo (como parques temáticos ou balneários, tal qual Cancún ou Costa do Sauípe), nem o distante lugar exótico, cuja atração se baseia em uma "autenticidade encenada" (MacCannell, 1976), mas também os centros urbanos se tornam destinos turísticos e, em verdade, os principais destinos, como Paris, Madri, Londres, Nova York, Berlim etc.

O caso de Nova York é exemplar e mereceu um brilhante estudo de Miriam Greenberg (2008), no qual me baseio neste momento. Imerso em uma crise fiscal e financeira desde a década de 1960, a "cidade do medo" lançou, em 1977, uma campanha que visava transformar sua imagem. A campanha não foi a primeira tentativa nesse sentido e a Feira Mundial de 1964-1965 em Flushing Meadows já fazia parte do projeto sem, contudo, encontrar o sucesso almejado. Mas a campanha de 1977 foi a primeira que teve o turismo como foco. Com uma marca desenhada por Milton Glazer, o mesmo designer responsável pela revista cult New York, a cidade lançou o programa cujo logotipo se tornaria um dos ícones mais reconhecidos e imitados globalmente. Tal qual já nos acostumávamos a fazer com os logotipos de marcas como de Yves Saint-Laurent ou Coca-Cola, agora reconhecíamos uma cidade em um ícone.

O foco no turismo levou a modificar a imagem de uma cidade historicamente relacionada aos movimentos operários - de tradição cultural operária (Berman, 2006) - para uma imagem de uma cidade de serviços e entretenimento, o "símbolo do neoliberalismo", na expressão de Greenberg. Como uma transformação de imagem orquestrada por grandes empresários do entretenimento, pela mídia especializa- 
da e pelo governo, cujas funções centrais relacionadas ao turismo eram coordenadas por interesses privados, toda uma história da cidade foi esquecida e outra foi construída ou destacada. A própria imagem recorrente da cidade - aquela da perspectiva a partir do sul de Manhattan -, em que se destacam os arranha-céus liderados, até 2001, pelo World Trade Centre, só se tornou comum a partir dos anos 1980.

FIGURA 1

MARCA NY



Entre o lançamento da campanha e hoje, de fato Nova York se transformou em uma cidade turística. Em 1976, estiveram lá 16,5 milhões de turistas, que gastaram U\$ 500 milhões (Greenberg, 2008: 215). Em 2013, 54,3 milhões de turistas gastaram U\$ 38,8 bilhões (NYC, 2014). Dessa forma, enquanto o número de turistas aumentou 3,2 vezes desde o lançamento da campanha "I $\bullet$ NY", os gastos com turismo aumentaram 77,6 vezes. Em que pese a inflação no período, mas também o crescimento populacional, o turismo se mostrava um setor peculiarmente atraente para a valorização do capital, tornando "a competição entre as cidades [...] mais frenética com o passar dos anos" (Fainstein \& Judd, 1999: 2).

Os números e a história narrada sobre Nova York ressaltam a importância do turismo para a valorização do capital, que se dá pela imbricação, tipicamente contemporânea, entre viagem e consumo. Dessa forma, o objetivo dos órgãos de turismo não é somente aumentar o número de turistas que visita um lugar - número este, de qualquer modo, finito e sempre difícil de se expandir -, mas fazer com que cada turista consuma cada vez mais, aumentando seu gasto individual.

John Urry (2011: 151) já notara que a "proliferação de opções" de lazer é tipicamente atual na prática do turismo. De fato, uma função dos órgãos oficiais de turismo é o aumento incessante do número de atrações e de roteiros turísticos, propondo ao turista cada vez mais opções de consumo ${ }^{7}$ e sempre novos motivos para seu retorno. No linguajar comum dos agentes do mercado de turismo, busca-se aumentar a quantidade "de produtos na prateleira". A Embratur celebrava que, em 2007, 18 "destinos nacionais" eram "vendidos" em catálogos de operadores de turismo estrangeiros, enquanto em 2004 ainda eram apenas cinco (Embratur, 2007: 47). O turista é apreendido justamente como um portador de capital (como de fato entendem os agentes de turismo); interpreto que um elemento dessa proliferação de opções se dá justamente no intuito da intensificação e repetição dos gastos dos turistas.

7. Em entrevista feita em 10 de junho de 2013, a representante da SPTuris me informou que uma de suas tarefas centrais dentro do que chama de Agenda 16 (planejamento do órgão até 2016) é a criação de roteiros temáticos em São Paulo. Até o momento da entrevista nove haviam sido criados. Hoje já são onze. 
Mas não é apenas esse processo que eleva a quantidade de acúmulo de capital em um lugar, a negociação dos preços dos produtos e a imagem dos lugares são centrais. Como em qualquer mercado, busca-se elevar ao máximo o preço dos produtos até o limite em que ele seja aceito pelo comprador. No turismo, isso se faz por um processo de constante incremento de signos sobre um produto. Um exemplo da pesquisa de campo ilustra um processo amplo. Um informante, especialista em turismo local, entrevistado em agosto de 2013 na cidade de Cuiabá (MT), argumentava que o problema do turismo naquele estado é não saber "agregar valor aos produtos". Dessa forma, se um suco de laranja - ele exemplificava - custa R\$ 2,00 em Nobres (MT), em Bonito (MS) custa R\$ 8,00, pois na cidade do sul mato-grossense o suco não é apenas um suco, mas um suco em uma jarra especial, servido em uma baixela especial, por um garçom altamente treinado etc.

Embora real (o mercado de turismo se utiliza de ferramentas simples para o incremento do preço dos produtos), essa visão deixa de fora uma dimensão mais ampla que interfere nos preços. Refiro-me justamente à imagem do lugar, que, no caso do setor de turismo (não me interessa discutir outros setores), diretamente impacta o valor dos produtos turísticos ali consumidos. Nessa dimensão, o processo envolvido se refere a tornar o espaço em si em espaço de maior valor. Volto a isso quando falar de marca-lugar, mas lembro aqui apenas algo que desenvolvi em outro texto, como forma de ilustração do argumento. Dediquei-me então à compreensão das imagens que a Embratur buscou produzir no contexto da Copa do Mundo de 2014 (Nicolau Netto, 2014). Pude identificar que as imagens se encontram, em primeiro lugar, de acordo com repetidas práticas internacionais, imagens essas ordenadas em torno de dois eixos que podem ser expressos pelas ideias de diversidade e modernidade, vocábulos amplamente repetidos nos documentos da Embratur. A diversidade se relaciona, como argumentei acima, com a ampliação das ofertas de consumo. A modernidade é articulada como forma de gerenciamento dessa diversidade. A partir da análise de imagens e discursos utilizados pela entidade, propus que a ideia de modernidade fosse afirmada em um processo que seleciona da diversidade os elementos que demonstrem maior valor de consumo, ou seja, maior valor agregado. Para que não se fale de forma demasiadamente abstrata, sem me forçar à análise de imagens - que não é o objetivo aqui -, observa-se nos vídeos da Embratur uma quantidade imensa de práticas e destinos turísticos, e de origens étnicas de turistas. Contudo, algo atravessa essa diversidade: predominam nas imagens práticas relacionadas a um consumo de alto padrão e vemos agora turistas em

8. Convido o leitor a assistir ao vídeo, disponível em: $<$ http://www. dailymotion.com/ video/x2o1cj5>. passeios de balão, em lojas, em restaurantes etc ${ }^{8}$. Ainda, homens de negócios em modernos centros de eventos ganham destaque nas imagens. A questão de negócios, de fato, é central e a Embratur não se cansa de lembrar em seus documentos que o turista de negócios e eventos gasta US\$280,00 por dia, enquanto aquele de 
lazer, US\$ 68,00 (Embratur, 2010: 17). Dessa forma, as imagens construídas não marcam apenas a Embratur, são constantes no mercado de turismo: de um lado, buscam induzir um tipo de turismo relacionado ao consumo; de outro, indicar esse consumo a partir de um alto padrão de valor. As estratégias da Embratur não deixam dúvidas sobre isso:

Os objetivos gerais de crescimento do turismo no país no período 2007-2010 passaram a priorizar o crescimento da entrada de divisas no país, indicada pelo Banco Central (Embratur, 2010: 85) ${ }^{9}$.

Dessa forma, competir por turistas se tornou uma prática central de atração de um capital desnacionalizado para grande parte dos países do mundo. E, "para competir por turistas, um local deve se tornar um destino" (Kirshenblatt-Gimblett, 1998: 152). Essa afirmação prosaica envolve um processo complexo que podemos relacionar com o que Henri Lefebvre chamou de produção do espaço, no sentido de perceber o espaço como processo e, ainda que pareça "inocente ou, em outras palavras, algo não político" (Lefebvre, 2009: 2207), como um "produto social" (Lefebvre, 2009: 2230). Para o autor, a noção de produção se relaciona a uma visão histórica do espaço que se apresenta como tal de acordo com as relações de produção vigentes. Dessa forma, cada relação de produção tem sua forma espacial e as "novas relações sociais demandam um novo espaço, e vice-versa" (Lefebvre, 1991: 59), sendo que uma revolução nunca é completa enquanto não mudar, de forma sistemática, o espaço.

Para definir o espaço como um produto social, Lefebvre lança mão de uma tríade conceitual. A primeira categoria, de "prática social" se refere ao espaço percebido em seus objetos como resultado de um processo de produção que o faz distinto, de acordo com a lógica das relações sociais vigentes. Mas o espaço também é representação e as "representações do espaço" são as ideologias dominantes que dão certos sentidos - códigos - de decifração do espaço. As representações são o espaço, portanto, concebido e científico que serve ao domínio simbólico. Por fim, Lefebvre fala do "espaço representacional", que é o espaço vivido em torno de uma série de símbolos articulados por seus próprios habitantes ou usuários, mas também artistas. É um espaço de resistência à representação dominante, que busca ir além dela (Lefebvre, 1991: 33 e 39).

Se interpreto corretamente Lefebvre, em seu materialismo, sua tríade conceitual ainda concerne à produção física do espaço. As representações do espaço se referem a sentidos dados a objetos materiais "na forma de prédios, monumentos, trabalhos de arte" (Lefebvre, 1991: 33). Do mesmo modo, o espaço representacional
9. Os números que eu poderia trazer são aqueles retirados dos relatórios da Embratur, facilmente acessíveis pela internet no link: $<$ http://www. dadosefatos.turismo. gov.br/dadosefatos>. Acessado em: 20 Ago. 2015). Esses números demonstrariam justamente um crescimento proporcional maior das divisas em relação ao número de turistas. Contudo, há razões - que aqui não se cabe explorar - para questionar a precisão das métricas utilizadas, o que torna prudente não se fiar demasiadamente nos dados. De qualquer forma, para os intuitos deste texto, em que não se busca uma avaliação das políticas de turismo no Brasil, mas compreender os sentidos dessas políticas, a intenção da Embratur em se focar no aumento da atração de divisas corrobora a tese da importância do turismo para a valorização do capital. 
também diz respeito aos objetos que dão sentido ao espaço, um sentido muitas vezes diferente do planejado. Dessa forma, o universo simbólico é a todo tempo subsumido ao material, importando, por exemplo, o sentido que um prédio dá ao espaço e não o sentido construído simbolicamente a este espaço para seu consumo e que passa a significar o objeto do espaço.

O turismo, argumento, se produz nos dois sentidos. Se está correto pensar a partir de Lefebvre que o turismo se relaciona à produção social do espaço, e que as relações sociais são o elemento central dessa produção, é importante pensar que hoje o espaço é produzido simbolicamente, em uma dinâmica que não coincide necessariamente com a produção física. A produção simbólica do espaço se relaciona a uma economia que hoje se torna cada vez mais autônoma e central à reprodução do capital, uma economia que John Urry e Scott Lash (1994) chamaram de economia dos signos. Neste sentido, o espaço é estetizado, mas não apenas no sentido de seu "embelezamento" (para alguns) para o turismo, mas também no sentido de se tornar signo, em oposição a outros signos, mas que guarda com esses um sentido cambiável, que é então articulado por diversos agentes para a valorização do capital. Um exemplo serve aqui.

10. Pesquisa de campo em Mato Grosso, entre julho e agosto de 2013

Observei em pesquisa de campo ${ }^{10}$ nas representações antigas encontradas em catálogos de agências de turismo e em materiais da Secretaria de Estado de Desenvolvimento de Turismo do Mato Grosso que os animais que mais se destacavam eram o tuiuiú e o jacaré. A onça não figurava em nenhum desses materiais, figurando, contudo, como elemento central nos mais contemporâneos, tal qual a imagem da

FIGURA 2

\section{BOLSA MT}

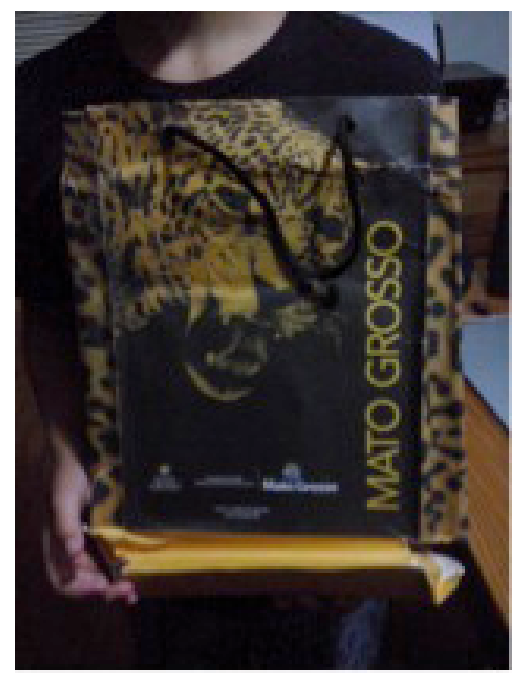

bolsa que a Secretaria distribuía na feira de turismo de Madri (Fitur), onde seus representantes buscavam promover o turismo internacional daquele estado.

A novidade da representação da onça foi notada pelo trabalho de Mara Alice Ribeiro (2014). Como afirma a autora:

Até 30 anos atrás, a onça era vista pela comunidade pantaneira como um animal hostil, uma ameaça, que deveria ser abatida porque ela causava prejuízos econômicos. E hoje este animal ascendeu a um status de objeto de desejo. Ter a onça na fazenda, cuidar do bicho, significa aumento de renda para a pousada.... E estas pessoas que estão lá entendem, muitas vezes, este processo que transformou o animal hostil em espetáculo da natureza (Mara Alice Ribeiro (2014), apud Anunciação, 2014). 
Esse processo que transforma a onça não apenas em atrativo turístico, mas em símbolo do lugar, envolve diversos agentes relacionados ao setor do turismo. Não me cabe aqui expor o complexo processo, mas anotar que a valorização da onça se dá no momento em que operadoras internacionais de turismo passaram a trabaIhar o Pantanal também como destino de natureza e aventura, similar aos safáris africados e asiáticos. Desta forma, no lugar dos tigres e dos leões, as operadoras passaram a demandar das filiais brasileiras elementos similares. É neste contexto que a onça, antes uma imagem inexistente, se torna hoje o signo central que define aquele espaço, em verdade o passeio mais caro que um turista pode fazer. Nota-se, assim, que não há aqui uma mudança física do espaço - a onça sempre esteve lá -, mas simbólica, que levou a uma nova produção do espaço, inserido em um contexto global.

\section{A marca Brasil}

Em referência à produção simbólica, ganha importância a noção de marca do lugar. Na década de 1990, retomando o sucesso de "I $\bullet$ NY", as cidades e os países passaram a adotar estratégias de inserção e atração do capital global. O marketing se tornou ferramenta importante nesses esforços e surgiu uma área nas universidades, especialmente dos Estados Unidos e do Reino Unido, especializada nisso: nation ou place branding. A suposição que embasa o termo, segundo um dos autores-referência na área, é a seguinte:

Minha observação original foi simples: que as reputações dos países são como as imagens de marca das empresas e produtos, e igualmente importantes (Anholt, 2007: XI).

Justamente como argumentei acima sobre a agenda privada das funções públicas, a marca-lugar pressupõe uma coincidência entre produtos e países ou cidades. Um outro autor afirma:

Do mesmo modo como produtos e serviços, cidades tornadas marcas (branded) são promovidas por estratégias de branding (Kemp, Childers \& Williams, 2012),

ou ainda,

o conceito de "brand" [quando aplicado à nação] permanece o mesmo invariante, ou seja, um grupo de valores que permite uma nação fazer promessas sobre uma experiência única e bem-vinda (Chernatony, 2008). 
11. Ver: <www simonanholt.com> Acessado em: 16 Nov. 2014.

O crescimento dessa área do marketing é contemporâneo ao surgimento de empresas que passam a oferecer serviços aos poderes públicos a fim de transformar os lugares em brand. Em verdade, a separação entre os centros de pesquisa e as empresas de consultoria não é clara, e uma série de "intelectuais" da área são eles próprios donos de empresas. É o caso do próprio Simon Anholt, acima citado, cuja empresa presta consultoria para

governos nacionais, regionais e de cidades para o desenvolvimento e implementação de estratégias para melhorar o engajamento econômico, político e cultural com outros países ${ }^{11}$.

Também é o caso do catalão Josep Chias, autor de livros sobre marketing de lugares e turismo (Chias, 2005), e fundador da empresa Chias Marketing.

Foi essa empresa a responsável pelo projeto de marketing da cidade de Barcelona no contexto das Olimpíadas de 1992. Em razão desse trabalho, Chias conheceu um mestrando em turismo pela USP que fora a Barcelona no fim dos anos 1990

FIGURA 3

MARCA BRASIL

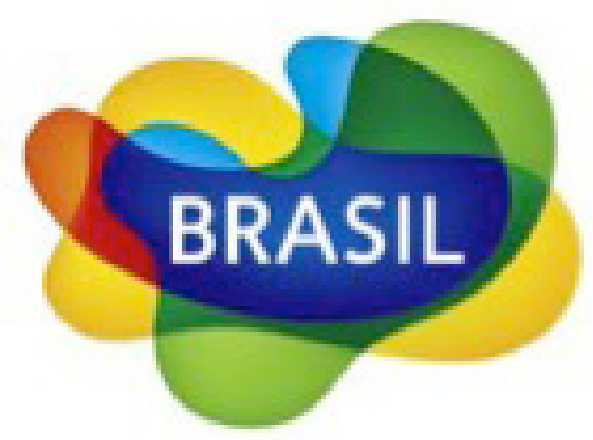

Sensational! justamente para estudar o projeto ali desenvolvido. Dessa experiência de pesquisa, que resultou em sua dissertação (Sanovicz, 2001), Eduardo Sanovicz trouxe ao Brasil a amizade com Chias. Em 2003, Sanovicz, de larga experiência pública no setor de turismo (fora presidente da SPTuris e do São Paulo Convention Bureau), tornou -se presidente da refundada Embratur e trouxe Josep Chias ao Brasil para desenvolver o primeiro Plano Aquarela: Marketing Turístico Internacional do Brasil (Embratur, 2005). Deste plano surge a marca Brasil, seguindo uma tendência que neste momento já se espalhava pelo mundo.

Ao mesmo tempo em que as empresas oferecem seus serviços, elas encontram demanda em todos os lugares. Hoje praticamente todos os países e as mais importantes cidades do mundo possuem um projeto de branding. A filial brasileira da própria Chias Marketing, segundo entrevista feita por mim com dois de seus representantes (16 de julho de 2013, em São Paulo), trabalha ou já trabalhou com várias cidades e estados brasileiros: Curitiba, Rio de Janeiro, Paraíba, Pará, Santa Catarina e São Paulo. 
A visão de lugar como marca representa um novo modo de significação do espaço que se relaciona diretamente com a noção de que a competição entre os lugares se dá em função da atração de um capital desnacionalizado, expresso no turismo. Dessa forma, a construção da imagem também se desnacionaliza e mesmo os agentes nacionais assumem processos "orientados para agendas e sistemas globais" (Sassen, 2006: 3). Notemos que a base para o desenvolvimento da marca Brasil se deu a partir da visão sobre o país de representantes do turismo no Brasil, de operadoras de turismo internacionais, e de turistas estrangeiros, entrevistados tanto no Brasil, quanto fora, sendo esses últimos divididos entre aqueles que já visitaram o país e os que nunca o visitaram ${ }^{12}$.

Assim, muito embora seja um órgão de jurisdição nacional, que participa do governo brasileiro, a atuação da Embratur é global, o que a leva a adotar uma marca que representa o Brasil a partir de visões produzidas no espaço global. A orientação global da entidade também se nota pela participação em feiras internacionais de turismo. Se em 2002 a Embratur participou de 15 feiras, em 2006 foram 40 (Sanovicz, 2007: 44). É marcante que nessas feiras as mesas e cadeiras do estande da Embratur não são ocupadas apenas por empresas brasileiras, mas também estrangeiras. $\mathrm{Na}$ feira de turismo FIT-Buenos Aires ${ }^{13}$, em 2013, havia todo um espaço reservado no estante da Embratur para operadoras de turismo argentinas que vendiam viagens ao Brasil, sendo que elas apareciam no catálogo da feira embaixo do nome Brasil. Ou seja, até mesmo os espaços nacionais dentro da globalização são operados por agentes globais.

Ao mesmo tempo em que a construção simbólica do lugar se desnacionaliza, sua afirmação precisa se fincar em uma ideia de nação. É por ela que o espaço se diferencia - transforma-se em obra, para dizer como Lefebvre (1991) - mostra-se única para atração do capital. Por isso, a marca precisa se basear na identidade. É neste sentido que podemos entender que na globalização as identidades nacionais se reforçam, ao invés de desaparecerem. A importância da identidade para a marca-lugar fez com que Simon Anholt (2007), em mais recentes trabalhos, se utilizasse da expressão "identidade competitiva", indicando que a disputa entre nações se dá em termos de valorização de suas identidades. Dessa forma, Anholt cria um índice de comparação das nações e das cidades (Nation branding index e City branding inde ${ }^{14}$ ), hierarquizando as identidades (Anholt, 2007: 67), tal qual uma marca.

A disputa da identidade nacional se desloca do Estado-nação para o espaço global, onde agentes globais e desnacionalizados disputam suas formações. Como retomarei a seguir, em relação à Copa do Mundo, diversos agentes globais se interessam pelas identidades dos países como forma de valorizar suas marcas. Dessa forma,
12. Informações obtidas em texto escrito por Eduardo Sanovicz e a mim enviado após uma entrevista feita em 3 de maio de 2013, em São Paulo. Um texto bastante similar a esse, que mantém as informações essenciais, pode ser encontrado na primeira versão do Plano Aquarela (Embratur, 2005) e na tese de doutorado de Sanovicz (Sanovicz, 2007: 92-93).

13. Pesquisa de campo realizada em setembro de 2013.

14. Ver: <http:// www.simonanholt. com/Research/ researchintroduction.aspx> Acessado em: 20 Ago. 2015. 
tanto a pluralização de agentes interessados nas identidades nacionais, quanto à importância que essas adquirem na formação da marca do lugar fazem com que países e cidades criem órgãos especializados neste trabalho.

Em geral esses órgãos se confundem com os órgãos responsáveis pelo turismo. Isso não se dá apenas pela importância do turismo nesse processo, mas também pelo fato de que esses órgãos tradicionalmente trabalharam com a imagem do país. É o caso da Embratur, órgão fundado em 1966 com a incumbência burocrática de administração do turismo brasileiro (indicando estrelas para hotéis, restaurantes; criando cadastros de profissionais etc.), mas que, especialmente a partir da década de 1970, se dedicou à produção de uma imagem do Brasil no exterior. O intuito dessa produção era menos a atração de turismo ao país - algo que de fato apenas de desenvolve a partir da década de 1990 com a adoção dos programas de incentivo chamados Prodetur (Dantas, Ferreira, \& Clementino, 2010) - mas a contraposição da imagem já reconhecida no exterior de um país sob forte regime opressor. À violência, contrapôs-se a festa do carnaval; ao sofrimento, a alegria; à opressão o sexo fácil e liberal (Kajihara, 2008; Alfonso, 2006).

Em 2003, o Ministério do Turismo é criado e esta pasta absorve todo o trabalho burocrático da Embratur, em termos de administração turística, e libera o Instituto (novo nome, que substitui Empresa, sem modificar o acrônimo) para se dedicar exclusivamente ao "marketing turístico internacional do Brasil", algo que a entidade vem fazendo desde então tendo por base seus planos Aquarela, que hoje estão na terceira versão (Embratur, 2010; Embratur, 2007; Embratur, 2005). Neste momento o Instituto segue a tendência de órgãos de outros países e passa a atuar como administrador simbólico.

A necessidade de se portar como um administrador simbólico se dá em um contexto, justamente, em que a produção da imagem do país se globaliza e a entidade se esforça a garantir o controle desta produção. Há diversas ferramentas que a Embratur - ferramentas essas usadas por todos os órgãos congêneres no mundo - se utiliza para a busca do controle da imagem. Como exemplos, o Instituto promove uma série de viagens de operadoras de turismo ao Brasil, desenvolve workshops de treinamento com profissionais estrangeiros em feiras de turismo internacionais, distribui materiais promocionais com "ensinamentos" sobre o Brasil, empreende ações administrativas ou mesmo judiciais contra agentes que se utilizam de imagens indesejadas do Brasil etc. Não há espaço aqui para detalhar essas ações, mas dou um exemplo para que se perceba que esse controle atinge mesmo as relações pessoais. O uso intenso feito pela Embratur de imagens de mulheres seminuas nas décadas de 1970 e 1980 encontrou oposição no setor turístico, especialmente a partir do 
momento em que o turismo sexual e, mais especificamente, a "exploração infantil em turismo sexual", se tornaram práticas condenadas internacionalmente pela Declaração sobre Prevenção do Turismo Sexual Organizado da Organização Mundial de Turismo, durante sua XI Assembleia Geral ocorrida em 1995 no Egito. Segue disso que em 1997 a Embratur criou um programa para se contrapor ao turismo sexual e, desde então, as imagens de mulheres diminuíram nas promoções da entidade até que, desde 2002, nenhuma imagem com esse conteúdo fosse utilizada (Kajihara, 2010: 18). Para manter o controle sobre a produção de uma imagem que o próprio Instituto incentivou por anos, a Embratur empreendeu uma série de processos contra aqueles que insistiam em seu uso. Em 2009, por exemplo, a Embratur processou e proibiu a circulação do guia turístico Rio for partners, no qual mulheres cariocas eram chamadas de "máquina do sexo"15. E esses esforços transparecem nas relações de interação encontradas nas feiras de turismo, espaço central utilizado pela Embratur na promoção da imagem do Brasil. Na feira FIT-Buenos Aires, ocorrida em setembro de 2013, o estado do Espírito Santo montou um pequeno estande de exposição ao lado daquele da Embratur. Seus representantes decidiram focar a promoção do turismo do estado no carnaval, em oposição às recomendações do órgão nacional. De acordo com entrevista (14 de setembro de 2014) a mim concedida in loco pelo secretário de Turismo do estado, a intenção de se focar no carnaval - uma imagem pouco associada ao Espírito Santo - se dava porque lá a festa começa uma semana antes do que no resto do país, o que facilitaria a atração de turistas. Para promover o evento, havia uma mulher vestida em um pequeno biquíni que passou o primeiro dia da feira sambando em frente ao estande.

A imagem que o Estado promovia ia exatamente na contramão da posição da Embratur, e a diretora de mercado internacional do Instituto proibiu a moça de entrar no estande nacional. Passo contínuo, a representante da Embratur chamou o representante do estado para uma conversa no intuito de convencê-lo a vestir a moça. No dia seguinte a essa conversa, a mesma moça sambava em frente ao estande do Espírito Santo, agora trajando um longo e apertado vestido. A diretora da Embratur assim narrou-me a conversa com o representante capixaba (Buenos Aires, 15 de setembro de 2014):
15. Disponível em: <http://g1.globo. com/Noticias/ Rio/0,,MUL12802405606,00-JUSTICA+P ROIBE+GUIA+QUE+ CHAMA+AS+CARIO CAS+DE+MAQUINA S+DE+SEXO.html>. Accessado em: 23 Jan. 2014.
Chamei o rapaz e falei, "olha, há muitos anos a gente vem trabaIhando o atrativo turístico brasileiro sem incluir a mulher, sem mostrar o corpo da mulher... E você vem aqui e traz uma mulata - graças a Deus muito bonita, pois não está denegrindo a imagem da muIher brasileira - mas você tem outras formas. Você bota um vestido nela, vestido justinho... não precisa ser um vestido até o pé... vestido curto, justo, ela com penacho na cabeça vai estar muito bonita. Faz uma roupa com paetê, vai estar muito vistosa, muito bonita. 
Não precisa estar nua". Aí falei pra ele, "você está cometendo três pecados básicos: 1. expondo o corpo da mulher brasileira; 2. você está colocando em risco a imagem da prefeitura da sua cidade, você está colocando em risco a imagem da sua cidade e as mulheres de sua cidade; 3. você está fazendo isso com dinheiro público".

O gerenciamento da imagem, empreendido pela Embratur, está vinculado a outra tarefa desses administradores simbólicos: o alcance da imagem. Ao mesmo tempo em que diversos agentes, globais ou desnacionalizados, atuam na produção da imagem, as imagens propostas enfrentam uma intensa competição. Isso se dá, como já vimos, pelo próprio aumento no interesse da imagem dos lugares por diversos agentes como forma de atração de um capital desnacionalizado, assim como pela pluralização da produção de imagem.

\section{A disputa pela marca Brasil e a hierarquização da representação do espaço}

É neste contexto que ganham importância os megaeventos e agora retomo esta temática. Eles são vistos por governos como forma de promover de maneira massiva a imagem dos lugares, uma forma privilegiada devido ao alcance que estes eventos têm em termos de mídia. A Embratur, de fato, se utilizou da Copa do Mundo em suas ações promocionais, ao menos desde 2012. Nas feiras de turismo, como a de Madri e de Buenos Aires, o tema central do estande foi o evento e o foco promocional foram as cidades-sede.

Ainda, a entidade organizou a série de eventos Goal to Brazil tendo como foco as cidades-sede da Copa. Em todos esses eventos, as doze cidades-sede dispunham de

FIGURA 4

ESTANDE BRASIL-FITUR

EMBRATUR, FITUR-MADRI (FEVEREIRO, 2013)



um pequeno espaço enfeitado com suas imagens e sons, onde seus representantes encontravam operadores de turismo internacional, tendo como objetivo vender suas cidades como destino turístico. As imagens apresentadas foram feitas na edição ocorrida em Madri, nos dois dias anteriores à feira de turismo Fitur.

A entidade também dedicou três vídeos promocionais ao contexto da Copa do Mundo. O primeiro, The world meets in Brazil: come celebra- 
te life, foi lançado em 2013. Os outros dois - Encontro e Dança - foram lançados mais próximos à Copa do Mundo. Esses vídeos foram exibidos pela Embratur em seus estandes, em seus canais do YouTube $^{16}$ e em programações de canais de TV de catorze países (Estados Unidos, Argentina, Chile, Peru, Colômbia, México, Alemanha, Reino Unido, Portugal, Espanha, Itália, Canadá, Holanda, França $)^{17}$.

O esforço da Embratur em promover certas imagens do Brasil no contexto da Copa do Mundo, contudo, é paralelo ao esforço de várias empresas em promoverem seus produtos se atrelando a certas imagens do Brasil. Tendo por base a noção de que a identidade de um país se declina em uma marca que possui valor no mercado global de símbolos, uma série de empresas buscam transferir esse valor a suas próprias marcas. Passe-se, então, o que Michael L. Silk et alii denominaram "nacionalismo corporativo" (Silk, Andrews, \& Cole, 2005: 7).

Para se compreender isso, precisamos lembrar que os megaeventos se tornaram eventos midiáticos, cada vez mais voltados para a proteção e a exposição das marcas

FIGURA 6

GOAL TO BRAZIL 1

EDIÇÃO MADRI, JANEIRO DE 2013



FIGURA 7

GOAL TO BRAZIL 2

EDIÇÃO MADRI, JANEIRO DE 2013

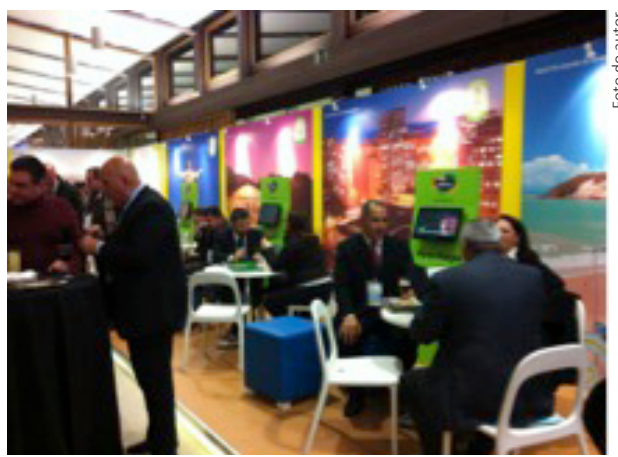

16. Ver: <https:// www.youtube.com/ user/visitbrasil>.

17. Informações passadas pela diretoria de marketing da Embratur em e-mail recebido em 25 de junho de 2014 
18. Obtive

acesso à carta de candidatura da CBF à Fifa, assinada pelo então presidente da entidade, Ricardo Teixeira, e às garantias governamentais para a realização do evento (anexas à carta) com base na lei do acesso à informação (Lei n.ำ 12.527/2011. <www. acessoainformação. gov.br>). 0 documento se chama "Brasil 2014 Bid Nation". Meu pedido se deu em 3 de junho de 2014 e obtive o documento em 6 de junho de 2014. dos patrocinadores e parceiros da Fifa. Isso se observa, por exemplo, nas exigências da entidade em que suas marcas e as marcas de seus parceiros sejam protegidas por lei. Dessa forma, a entidade registrou para a Copa de 2014 no Instituto Nacional da Propriedade Industrial (INPI) 1.116 marcas, sob a garantia da Lei n.o 12.663/2012, que reproduziu a oitava das onze garantias governamentais que o Brasil assinou no intuito de se candidatar a sediar o evento, garantia essa que versava sobre "proteção e exploração de direitos comerciais"18.

Ainda, a Fifa garantiu, a partir de 2002, um controle pleno sobre as imagens do evento quando passou a ser ela própria, através da empresa Host Broadcast Services (HBS), a responsável por sua transmissão, em detrimento das emissoras locais. Assim, todas as imagens relacionadas aos jogos eram geradas pela entidade e todas as emissoras licenciadas eram obrigadas a transmiti-las. Isso incluía não apenas as partidas em si, mas os momentos que antecediam aos jogos (o que incluía a vinheta da Fifa, a entrada dos jogadores, o hino e a longa exposição da bola Adidas) e os que sucediam (o que incluía a entrevista de um jogador de cada time em frente a uma placa com patrocinadores da Fifa). Nem mesmo repetições de lance durante este tempo ou as antigas câmeras exclusivas das emissoras locais foram permitidas, foram mesmo proibidos nos estádios equipamentos como

computadores pessoais e outros dispositivos (incluindo, por exemplo, laptops ou PC tablets) usados para os fins de transmissão ou disseminação de sons, imagens, descrições ou resultados dos eventos pela internet ou outros meios (Fifa, 2013: alínea v).

Esse controle sobre a imagem e as marcas - que também se relacionava ao que poderia ser exibido dentro dos estádios e nos locais de reunião de torcedores, como as Fan fests - é sobre o que se baseia o faturamento da entidade com o evento. A máxima exposição da marca dos patrocinadores sob condições favoráveis garantidas pela Fifa a um público calculado em cerca da metade da população mundial (Fifa, 2011) certifica à entidade um crescente faturamento advindo em direitos de marketing. Assim, entre 1999 e 2002 a Fifa arrecadou US\$ 571 milhões (Fifa, 2003); entre 2003 e 2006, US\$ 856 milhões (Fifa, 2007); entre 2007 e 2010, US\$ 1,2 bilhão (Fifa, 2011). Estima-se que apenas pela Copa de 2014 a Fifa arrecadou em direitos de marketing US\$1,35 bilhões (Ozanian, 2014). Soma-se a este valor aqueles advindos de direitos de transmissão dos jogos e chega-se a $90 \%$ de toda a receita da entidade.

Dessa forma, as empresas que se envolvem comercialmente com a Copa do Mundo buscam promover suas marcas como forma de compensar os custos de seu patrocínio. Uma das maneiras, do ponto de vista simbólico, é buscando se atrelarem à imagem do país sede da Copa do Mundo. Como a Copa do Mundo promove o país-sede 
no espaço global e que essa imagem será valorizada neste contexto, as empresas adotam campanhas que buscam transferir tal valor para suas marcas e imagens. É disso que se trata o nacionalismo corporativo. No caso da Copa do Mundo, inúmeras empresas adotaram essa estratégia. Para citar apenas algumas que tiveram amplo alcance mundial, lembro que Hyunday ${ }^{19}$, Nike ${ }^{20}$, Coca-Cola ${ }^{21}$, além do clipe oficial da Copa do Mundo, da gravadora Sony Music ${ }^{22}$, desenvolveram campanhas promocionais tendo uma noção sobre identidade nacional do Brasil como tema central.

Ainda, as próprias imagens que a Fifa se utilizou para traçar o leiaute geral do evento trouxeram signos relacionados ao Brasil. A adoção de um animal típico da fauna brasileira, o tatu bola, como mascote; as cerimônias de abertura e encerramento da Copa do Mundo; a vinheta de abertura das transmissões dos jogos (com o menino que joga bola na favela e observa os estádios pelo país ${ }^{23}$ ); o clipe da canção oficial, em parceria com a Sony Music (em que Jennifer Lopez, Pitbull e Claudia Leitte dançam em meio a um claro pastiche do carnaval) são exemplos de como a Fifa trabaIhou com a imagem do Brasil.

Repito que não me interessa aqui analisar as imagens em si, mas notar que a representação do Brasil se tornou o interesse de grandes corporações globais e a Embratur apenas um agente nessa disputa. O notável, contudo, é que a própria Embratur não pôde se utilizar dos espaços abertos pelo evento em si. Ao contrário das marcas que patrocinaram a Copa do Mundo, ao contrário mesmo da Fifa, a entidade brasileira não podia expor quaisquer de suas imagens nos espaços controlados pela entidade, nem mesmo influenciar as imagens exibidas nesses espaços. Dois exemplos importam aqui.

Costa do Sauípe foi escolhido como o lugar do sorteio das chaves da Copa do Mundo, momento este de maior atração midiática global fora do evento em si. Levando-se em conta que o governo entende a Copa como momento de promoção da imagem do Brasil no exterior e que a Embratur é a entidade central deste processo, seria de se supor que a escolha da Costa do Sauípe tenha sido uma decisão minimamente influenciada pelo Instituto. Indaguei sobre essa questão à gerente de mercados internacionais da Embratur, em entrevista ocorrida em Buenos Aires, em setembro de 2013. Sua resposta:

Não, nada do que se refere à Fifa tem dedo do governo brasileiro. Nada que se refere a decisões onde vai ser, como vai ser, que horas que vai ser, é tudo definido pela Fifa. O Fuleco está aqui, já tirou foto com o Fuleco? A Embratur paga para o Fuleco estar aqui. Paga para a Fifa. Eu acho isso um absurdo. Eu como funcionária acho isso absurdo. É o famoso contrato cara-cu, não tem outro.
19. Disponível em: $<$ https://www.youtube.com/watch?$v=\mathrm{OHhFGu4ZuTc>}$. Acessado em: 24 Nov. 2014.

20. Disponível em: <http://news.nike. com/news/nike-launches-the-dare-to-be-brasilian-campaign> Acessado em: 24 Nov. 2014

21. Disponível em: <http://www. coca-colacompany. com/fifa-world-cup/ everyones-invited-global-coca-cola-campaign-celebrates-inclusive-power-of-2014-fifa-world-cup>. Acessado em: 24 Nov. 2014.

22. Disponível em: <https://www.youtube.com/watch?$\mathrm{v}=\mathrm{TG}$ tWWb9emYl> Acessado em: 24 Nov. 2014

23. Disponível em: <https://www. youtube.com/watch?v=JP67IM1LX-M> Acessado em: 24 Nov. 2014. 
24. Conforme e-mail recebido em 25 de junho de 2014. Ver nota 10

25. Disponível em: $<$ http://www.fifa. $\mathrm{com} / \mathrm{mm} / \mathrm{docu}$ ment/affederation/ $\mathrm{tv} / 01 / 47 / 76 / 00 /$ 2014fifaworldcupbrazil(tm) mediarightslicenseelist240513_neutral. pdf $>$. Acessado em: 20 Nov. 2014.
Outro momento de grande visibilidade da imagem do Brasil relacionado à Copa do Mundo se deu através do clipe da música oficial da Copa, "Olé olá", já citado acima. Da mesma forma, indaguei sobre a influência da Embratur nas imagens ali presentes. Por e-mail, um responsável pela entidade afirmou que, uma vez mais, a Embratur não teve qualquer participação naquele vídeo e que a campanha da entidade se refere àquela composta pelos vídeos, aqui já citados, Dance e Encontros que destacam diversos atributos diferenciadores do Brasil: nossa cultura, a experiência inesquecível que representa visitar o país, os atrativos turísticos, assim como a alegria dos brasileiros ${ }^{24}$.

A Embratur esteve distante, portanto, dos espaços e das decisões centrais de representação da nação na Copa do Mundo. Mais importante, precisou buscar espaço para sua representação da nação, espaço esse necessariamente menos valorizado do que aquele das marcas diretamente relacionadas à Copa do Mundo: Fifa e patrocinadores. Se, como disse acima, a campanha promocional da Embratur foi veiculada em catorze países, fora dos momentos dos jogos, a vinheta da Fifa que abria cada jogo foi veiculada repetidamente, no momento de maior atenção do público, em todos os 239 territórios que retransmitiram os jogos ${ }^{25}$. Da mesma forma, a abertura e o encerramento da Copa e certamente, em grande medida, as propagandas das empresas globais patrocinadoras do jogo. Todos, assim, disputaram a representação do Brasil. Contudo, de maneira hierarquizada. É com essa noção que parto para as últimas palavras.

\section{Conclusão}

A imagem do lugar se torna importante na atração de um capital desnacionalizado, especialmente aquele relacionado com o turismo. Dessa forma os Estados nacionais criam órgãos legitimados como administradores simbólicos que operam no espaço global para a produção simbólica do espaço, buscando transformar a imagem do lugar em uma marca e, como tal, administrada em termos empresariais.

Os megaeventos esportivos se tornam plataforma central de promoção dessa marca, concorrida por cidades e nações, levando a imagem do país a um alcance global apenas imaginável em momentos de grande exceção que são, em geral, trágicos. Contudo, não há uma imagem sendo produzida do lugar, mas uma pluralidade delas. A ação dos administradores simbólicos, justamente no momento de maior relevância de suas ações, é limitada frente à dimensão dos interesses envolvidos. Surge, assim, aquilo que poderíamos chamar de hierarquização simbólica, segundo a qual a pluralização de imagens que representam a nação se espalha desigualmente pelo espaço global, de acordo com as condições de acesso a canais mais ou menos privilegiados. 
Para o caso que me interessou aqui, portanto, a representação do Brasil se hierarquiza na Copa do Mundo, mas não a partir do Estado-nação, como já vivenciamos, nem mesmo de um ente desnacionalizado deste Estado. A representação do Brasil se hierarquiza a partir de empresas globais que quanto mais próximas - econômica e administrativamente - da Copa do Mundo maiores condições apresentam para circular seus nacionalismos corporativos. À Embratur restam os espaços dissidentes, da margem do megaevento, ironicamente muito parecidos com o espaço de outro agente interessado na produção simbólica da nação: os descontentes com a Copa do Mundo. Os contentores, como vimos no começo deste artigo, ali se encontraram, longe da grande mídia, nas bordas do fluxo denso das imagens do evento, disputando de maneira fragilizada a representação do país.

Abstract: The pertinence of hosting the Football World Cup in Brazil has been a warm issue between 2013 and 2014. The debates were centered on two issues: the economic and the social impacts of the event. A third issue was also important, however, much less discussed: for its defenders hosting the games was justified by to opportunity to promote the country image abroad. Image promotion become a central issue in a moment in which countries of the whole world dispute the attraction of a flexible and denationalized capital. In this sense, identities are articulated as brand in order to produce symbolically the space as more attractive to the capital, something to be clearly noticed in the touristic promotion. This paper aims to understand the relationship between place branding and the promotion of country image in the World Cup context. It will be shown that, in the case of Brazil, there are several agents with interests on representing Brazil, what leads to a hierarchy of representation. This hierarchy is not given, however, by the nation-state, but by the global companies involved with the mega-event.

Keywords: World Cup, corporative nationalism, national identity, Embratur, Brazil.

\section{Referências}

ALFONSO, Louise Prado. Embratur: formadora de imagens da nação brasileira. Campinas: Unicamp, 2006.

ARTICULAÇÃO NACIONAL DOS COMITÊS POPULARES DA COPA (ANCOP). DosSiê megaeventos e violações dos direitos humanos no Brasil. Brasília: Ancop, 2014.

ANHOLT, Simon. Competitive identity: the new brand management for nations, cities and regions. New York: Palgrave Macmillan, 2007.

ANUNCIAÇÃO, Sílvio. Entre secas e cheias, irrompe a nova geografia pantaneira. Jornal da Unicamp, p. 12, 2014.

BERMAN, Marshall. On the town: one hundred years of spectacle in Times Square. New York : Random House, 2006. 
BOURDIEU, Pierre. O poder simbólico. Rio de Janeiro: Bertrand Brasil, 2004.

CARVAlHO, Caio Luiz de. Políticas públicas no turismo brasileiro: a cidade de São Paulo e a construção de sua identidade turística. Tese (Doutorado em Relações Públicas, Propaganda e Turismo) - Universidade de São Paulo, São Paulo, 2009.

CHADE, Jamil. A Copa como ela é - a história de dez anos de preparação para a Copa de 2014. São Paulo: Breve Companhia, 2014.

CHERNATONY, Leslie de. Adapting brand theory to the context of nation branding. In: DINNIE, Keith (Org.). Nation branding: concepts, issues, practice. Amsterdam: Routledge, 2008.

CHIAS, Josep. El negocio de la felicitad: desarrollo y marketing turístico de países, regiones, ciudades y lugares. Madrid: Pearson Educación, 2005.

DANTAS, Estógio Wanderly Correia; FERREIRA, Angela Lúcia; CLEMENTINO, Maria do LIvramento Miranda. Turismo e imobiliário nas metrópoles. Rio de Janeiro: Letra Capital, 2010.

DE PAULA, Marilene; BARTELT, Dawid Danilo. Copa para quem e para quê? um olhar sobre os legados dos mundiais no Brasil, África do Sul e Alemanha. Rio de Janeiro: Fundação Heinrich Böll , 2014.

ERNST \& YOUNG. Brasil sustentável: impactos socioeconômicos da Copa do Mundo 2014. São Paulo: Ernst \& Young: Editora FGV, s/d.

FAINSTEIN, Susan S.; JUDD, Dennis, R. Global forces, local strategies, and urban tourism. In: JUDD, Dennis R.; FAINSTEIN, Susan S. The tourist city. New Haven; London: Yale University Press, 1999.

FÉdÉRATION INTERNATIONALE DE FOOTBALL ASSOCIATION (FIFA). Código de Conduta no estádio para a Copa do Mundo da Fifa Brasil 2014. Fifa, Ago. 2013. Disponível em: <www.fifa.com>. Acessado em: 10 Ago. 2014.

- Almost half the world tuned in at home to watch 2010 Fifa World Cup South Africa. Jul. 2011. Disponível em: <http://www.fifa.com/worldcup/archive/ southafrica2010/organisation/media/newsid=1473143/index.html>. Acessado em: Jun. 2012.

_. Fifa financial report 2010. Fifa, 2011.
. Fifa financial report 2006. Fifa, 2007.
_. Fifa financial report 2002. Fifa, 2003. 
GREENBERG, Miriam. Branding New York: how a city in crisis was sold to the world. New York: Routledge, 2008.

HARVEY, David. A produção capitalista do espaço. São Paulo: Annablume, 2005.

HOLCOMB, Briavel. Marketing cities for tourism. In: JUDD, Dennis R.; FAINSTEIN, Susan S. The tourist city. New Haven; London: Yale University Press, 1999.

HORNE, John D.; MANZENREITER, Wolfram. Accounting for mega-events: forecast and actual impacts of the 2002 Football World Cup Finals on the host countries Japan/Korea. Internacional Review for the Sociology of Sport, v. 39, n. 2, p. 187-203, 2004.

INSTITUTE FOR HUMAN RIGHTS AND BUSINESS. Striving for excellence: mega-sporting events and human rights. Ocasional paper series. Oct. 2013.

INSTITUTO BRASILEIRO DE TURISMO (EMBRATUR). Plano Aquarela 2020 marketing turístico. Brasília: Embratur, 2010.

- Plano Aquarela marketing turístico internacional do Brasil - 2007-2010. Brasília: Embratur, 2007.

_. Plano Aquarela marketing turístico internacional do Brasil-2005. Brasília: Embratur, 2005.

IVO, Any Brito Leal. Una nueva copa en un nuevo país: intervenciones urbanas y creación de ciudades para el mundial de fútbol Brasil 2014. Bitacora , v. 18, p. 3954, 2011.

KAJIHARA, Kelly. A imagem do Brasil no exterior: análise do material de divulgação ofical da Embratur desde 1966 até 2008. Observatório de Inovação do Turismo Revista Acadêmica, n. 3, p. 1-30, 2010.

A imagem do Brasil no exterior: análise de material de divulgação oficial da Embratur desde 1966 até os dias atuais. Tese (Doutorado) - Fundação Instituto de Pesquisas Econômicas, Universidade de São Paulo, São Paulo, 2008.

KEMP, Elyria; CHILDERS, Carla Y.; WILLIAMS, Kim H. Place branding: creating self-brand connections and brand advocacy. Journal of Product \& Brand Management (Emerald Group), p. 508-515, 2012.

KIRSHENBLATT-GIMBLETT, Barbara. Destination culture: tourism, museums, and heritage. Los Angeles; London: University of California Press, 1998. 
LASH, Scott; URRY, John. Economies of signs \& space. London: Sage Publications, 1994.

LEFEBVRE, Henri. State, space, world: selected essays. Minneapolis: University of Minessota, 2009.

_. The production of space. Maiden; Oxford; Victoria: Blackwell, 1991.

MACCANNELL, Dean. The tourist: a new theory of leisure class. New York: Schocken Books, 1976.

MINISTÉRIO DO TURISMO (MTUR); FUNDAÇÃO GETÚLIO VARVAS (FGV). Proposta estratégica de organização turística: Copa do Mundo 2014 Brasil. Brasília: Mtur; FGV, s/d.

NICOLAU NETTO, Michel. Os sentidos da diversidade e da modernidade nas campanhas promocionais contemporâneas da Embratur. In: PONTES JR., Geraldo; CASTRO, Maurício Barros de; SANTOS, Myrian Sepúlveda dos (Orgs.). Diálogos interdisciplinares: literatura e políticas culturais. Rio de Janeiro: EdUERJ, 2015.

NEW YORK CITY (NYC). NYC statistics. NYC the official guide. 2014. Disponível em: <www.nycgo.com>. Accessado em: Nov. 2014.

ORTIZ, Renato. Mundialização e cultura. São Paulo: Brasiliense, 2003.

OZANIAN, Marc. World Cup Brazil will generate \$ 4 billion for Fifa, 66\% more than 2010 tournment. Forbes, Jun. 2014. Disponível em: <http://www.forbes.com/sites/ mikeozanian/2014/06/05/the-billion-dollar-business-of-the-world-cup>. Acessado em Ago. 2014.

PORTAL POPULAR DA COPA E DAS OLIMPÍADAS. Elitização e mercantilização da cidade. Portal Popular da Copa e das Olimpíadas, 2014. Disponível em: <www.portalpopulardacopa.org.br>. Acessado em: Nov. 2014.

PREUSS, Holger. Problematizing arguments of the opponents of olympic games. In: BARNEY, K. B.; WAMSLEY, S. G.; MARTYN; MACDONALD G. H. (Orgs.). Global culture and cultural critique: problematizing the Olympic Games. London: International Symposium for Olympic Research, 1998.

REJOWSKI, M. Turismo no percurso do tempo. São Paulo: Aleph, 2002.

RIBEIRO, Mara Alice. Entre os ciclos de cheia e vazante, a gente do Pantanal produz e revela geografias. Tese (Doutorado) - Instituto de Geociências, Universidade Estadual de Campinas (Unicamp), Campinas, 2014. 
ROCHE, Maurice. Mega-events and modernity: olympics and expos in the growth of global culture. London; New York: Routledge, 2000.

- Mega-events and micro-modernization: on the sociology of the new urban tourism. The British Journal of Sociology, p. 563-600, 1992.

SÃO PAULO TURISMO. Platum 2011-2014: plano de turismo municipal - cidade de São Paulo. São Paulo: São Paulo Turismo, 2010.

SAMPAIO JÚNIOR, Plínio de Arruda. Desenvolvimentismo e neodesenvolvimentismo: tragédia e farsa. Serviço Social \& Sociedade, p. 672-688, 2012.

SANOVICZ, Eduardo. A promoção comercial do turismo brasileiro no exterior: o caso da reconstituição da Embratur. Tese (Doutorado) - Escola de Comunicação e Artes da Universidade de São Paulo (ECA-USP), São Paulo, 2007.

- Proxima Estación Plaça Calalunya. Dissertação (Mestrado) - Departamento de Publicidade, Relações Públicas e Turismo da Escola de Comunicações e Artes, Universidade de São Paulo, São Paulo, 2001.

SASSEN, Saskia. A sociology of globalization. New York; London: W. W. Norton \& Company, 2007.

Territory, authority, rights: from medieval to global assemblages. New Jersey: Princeton University Press, 2006.

SECRETARIA GERAL DA PRESIDÊNCIA DA REPÚBLICA. Desapropriações e deslocamentos invonluntários na Copa Fifa 2014. Brasília: Secretaria Geral da Presidência. julho 2014. Disponível em: <www.secretariageral.gov.br>. Acessado em: Nov. 2014.

SILK, M.; ANDREWS, D. L.; COLE, C. Corporate nationalism(s)? The spatial dimensions of sporting capital. In: SILK, M; ANDREWS, D. L.; COLE, C. Corporate nationalism: sport, cultural identity and transnational marketing. Oxford: Berg, 2005.

TAVARES, Otavio. Megaeventos esportivos. Movimento, v. 17, n. 3, p. 11-35, Universidade Federal do Rio Grande do Sul, 2011.

URRY, John. Consuming places. London; New York: Taylor \& Francis, 2011.

VALENTE JÚNIOR, Airton Saboya. Mega sporting events and legacy: the case of the 2014 World Cup. Regional Studies, s/d. Disponível em: <www.regionalstudies.org/ uploads/Airton_Saboya_Valente_Junior.pdf>. Acessado em: Nov. 2014.

WEBER, Max. Bureaucracy. In: WRIGHT MILLS, Ch.; GERTH, H. H. (Orgs.). From Max Weber: essays in sociology. New York: Galaxy Books, 1958. 